\title{
Methylator phenotype of malignant germ cell tumours in children identifies strong candidates for chemotherapy resistance
}

\author{
JN Jeyapalan 1,6, DA Mohamed Noor ${ }^{1,6}$, S-H Lee', CL Tan', VA Appleby', JP Kilday², RD Palmer ${ }^{3}$, EC Schwalbe ${ }^{4}$, \\ SC Clifford ${ }^{4}$, DA Walker ${ }^{2}, \mathrm{MJ}$ Murray $^{3}, \mathrm{~N} \mathrm{Coleman}^{3}, \mathrm{JC}$ Nicholson $^{5}$ and PJ Scotting*,I \\ 'Children's Brain Tumour Research Centre, Centre for Genetics and Genomics, University of Nottingham, Queen's Medical Centre, Nottingham NG7 \\ 2UH, UK; ${ }^{2}$ Children's Brain Tumour Research Centre, Child Health, School of Clinical Sciences, University of Nottingham, Queen's Medical Centre, \\ Nottingham NG7 2UH, UK; ${ }^{3}$ MRC Cancer Cell Unit, Hutchison/MRC Research Centre, Box 197, Hills Road, Cambridge CB2 OXZ, UK; ${ }^{4}$ Northern \\ Institute for Cancer Research, Sir James Spence Institute, Newcastle University, Newcastle-upon-Tyne NE2 4HH, UK; ${ }^{5}$ Department of Paediatric \\ Oncology, Addenbrooke's Hospital, Box 181, Hills Road, Cambridge CB2 OQQ, UK
}

BACKGROUND: Yolk sac tumours (YSTs) and germinomas are the two major pure histological subtypes of germ cell tumours. To date, the role of DNA methylation in the aetiology of this class of tumour has only been analysed in adult testicular forms and with respect to only a few genes.

METHODS: A bank of paediatric tumours was analysed for global methylation of LINE-I repeat elements and global methylation of regulatory elements using GoldenGate methylation arrays.

RESULTS: Both germinomas and YSTs exhibited significant global hypomethylation of LINE-I elements. However, in germinomas, methylation of gene regulatory regions differed little from control samples, whereas YSTs exhibited increased methylation at a large proportion of the loci tested, showing a 'methylator' phenotype, including silencing of genes associated with Caspase-8-dependent apoptosis. Furthermore, we found that the methylator phenotype of YSTs was coincident with higher levels of expression of the DNA methyltransferase, DNA (cytosine-5)-methyltransferase 3B, suggesting a mechanism underlying the phenotype.

CONCLUSION: Epigenetic silencing of a large number of potential tumour suppressor genes in YSTs might explain why they exhibit a more aggressive natural history than germinomas and silencing of genes associated with Caspase-8-dependent cell death might explain the relative resistance of YSTs to conventional therapy.

British Journal of Cancer (201 I) I 05, 575-585. doi:I0.1038/bjc.201 I.218 www.bjcancer.com

Published online 28 June 2011

(c) 201 I Cancer Research UK

Keywords: germ cell tumour; yolk sac tumour; germinoma; methylation; paediatric

Changes in DNA methylation have been thought to have a role in cancer aetiology for many years (Feinberg and Vogelstein, 1983; Feinberg and Tycko, 2004). Although hypomethylation of repetitive elements has been shown in a range of cancer types, there is little evidence for hypomethylation of gene regulatory sequences (De Smet and Loriot, 2010). By contrast, analysis of many individual tumour suppressor genes has shown their repression by promoter hypermethylation in cancers to be commonplace. More recently, where global analyses have been applied, all classes of tumour analysed have shown high levels of methylation of many genes, suggesting that this is a widespread event in cancer development (Martin-Subero et al, 2009; Richter et al, 2009). Indeed, specific subgroups of colon cancer and glioma have been shown to exhibit a 'methylator' phenotype (Toyota et al, 1999; Weisenberger et al, 2006; Shen et al, 2007; Noushmehr et al, 2010).

Children's cancers develop over a very short time scale, many within the first few years and even perinatally. Unlike cancers in adults, this would not seem to provide time for a series of

\footnotetext{
*Correspondence: Dr PJ Scotting; E-mail: paul.scotting@nottingham.ac.uk ${ }^{6}$ These authors contributed equally to this work.

Received 16 February 2011; revised II May 2011; accepted 17 May 201 I; published online 28 June 2011
}

carcinogenically driven mutations to arise. Dysregulation of gene expression due to changes in global methylation through a defect in the methylation machinery provides a plausible alternative mechanism for the development of these childhood cancers.

Paediatric germ cell tumours (GCTs) are a particularly unusual group of cancers. They arise not only in the tissues where germ cells would normally reside, the gonads, but also in extragonadal sites, primarily the base of the spine (sacrococcygeal tumours), the thorax (mediastinal tumours) and in the ventral midline of the brain. In addition, they exhibit strikingly different histological subtypes that parallel the forms seen in adults, classified as seminomatous or non-seminomatous. The seminomatous tumours are uniform tumours resembling those found in adult testes with a similarity to germ cell progenitors (in extragonadal sites, and throughout this report, referred to as 'germinomas'). Nonseminomatous tumours represent several morphologically distinct subtypes, of which yolk sac tumours (YSTs) are the major class in children and which are therefore included in this study. In general, YSTs are relatively more aggressive and resistant to therapy than seminomatous tumours (Murray et al, 2010). Despite these differences, all GCTs are believed to share a common lineage, as both histological subtypes can exist in the same tumour (Looijenga, 2009) and primary seminomatous tumours can recur as non-seminomatous tumours (Wong et al, 2010). 
Like other paediatric tumours, GCTs may exhibit relatively few cytogenetic abnormalities and the teratoma subtype, for example, exhibits little or no cytogenetic damage (Rickert, 1999; Mostert et al, 2000; Veltman et al, 2003; Oosterhuis and Looijenga, 2005). Hence, in cases where DNA damage is not the primary cause of dysregulated gene expression, then it must be disrupted by another mechanism, for which DNA methylation is a strong candidate. For this reason, analysing the methylation status of the genome is of particular importance to our understanding of this class of tumour.

To date, DNA methylation has only been analySed with respect to a small group of genes in adult testicular GCTs (Koul et al, 2002, 2004; Smith-Sorensen et al, 2002; Honorio et al, 2003; Manton et al, 2005; Lind et al, 2006, 2007), which revealed the methylation of nine known tumour suppressor genes in a large number of tumours. However, no analysis has been carried out to determine if changes in methylation are seen in paediatric cases or in extragonadal GCTs.

To analyse methylation in a cohort of paediatric GCTs, we adopted two approaches. Firstly, we analysed the methylation status of the LINE-1 repetitive elements that are dispersed throughout the genome and have been shown to reflect the general methylation status of intergenic DNA. Secondly, we also used GoldenGate methylation arrays (Illumina, San Diego, CA, USA) to assess the methylation status of more than 800 genes. These experiments revealed a striking difference in methylation between YSTs and germinomas, which occurred irrespective of anatomical location, sex or age. This makes YSTs a very unusual histological class of tumour in which the great majority exhibit a highly methylated state, setting them apart from other types of cancer in which DNA methylation has been analysed to date. Our study identified a large number of potentially important methylation events that could contribute to the tumour's pathogenesis, among which the methylation of several genes correlated well with their expression levels between the two groups of tumours. Most notable among these were genes associated with the extrinsic pathway of apoptosis. Finally, we found that the 'methylator' phenotype in YST correlated with increased expression of $D N A$ (cytosine-5)-methyltransferase $3 B$ (DNMT3B).

\section{MATERIALS AND METHODS}

\section{Combination of bisulphite and restriction analysis}

LINE1 PCR was carried out according to Yang et al (2004) using $30 \mathrm{ng}$ of bisulphite converted (EZ DNA methylation kit, Zymo Research, Irvine, CA, USA) genomic DNA and Platinum Taq (Invitrogen, Paisley, UK), with $100 \mathrm{nM}$ of FAM-labelled forward primer and $100 \mathrm{~nm}$ reverse primer. Polymerase chain reaction products were then digested with Hinf1 restriction enzyme (NEB, Hitchin, UK). Digested products were analysed by gel electrophoresis and GeneScan (Applied Biosystems, Foster City, CA, USA). Primers sequences are shown in Supplementary information and Supplementary Table 3.

\section{Methylation microarray analysis}

Methylation array analysis was performed at the Wellcome Trust Centre for Human Genetics, University of Oxford, using the Illumina GoldenGate Cancer Panel I assay http://www.illumina. com/pages.ilmn?ID =193/, according to the manufacturer's instructions. The assay reports methylation values at 1505 loci mapping to 807 genes previously associated with DNA methylation and/or cancer.

Quality control was carried out using Beadstudio v.3.2 methylation module (Illumina) and the $\mathrm{R}$ package, beadarray (Dunning et al, 2007), which enabled the identification and exclusion of potentially confounding spatial artefacts. Samples failing quality control were removed from subsequent analyses. After background signal normalisation, the assay reported $\beta$-values for each measured probe, with values ranging from zero (unmethylated) to one (methylated) (Bibikova et al, 2006).

\section{Cluster analysis and identification of differentially methylated loci}

Bootstrapped hierarchical clustering was performed using the $\mathrm{R}$ package pvclust (Suzuki and Shimodaira, 2006), using Euclidean distance, average agglomeration and 10000 replications. Subgroups with an approximate unbiased $P$-value of $<0.05$ were significant. The observed clustering patterns were assessed using principal component analysis and $k$ means analysis. The optimal number of clusters for $k$ means analysis was assessed using Scree plots. Differentially methylated loci between subgroups were identified using Mann-Whitney $U$-tests, with a $P$-value $<0.05$ after Benjamini-Hochberg false discovery rate correction (Benjamini and Hochberg, 1995) for multiple testing, with an additional filter that the average change in $\beta$ between subgroups be $>0.2$. This was increased to $>0.34$ for comparison between tumour subtypes.

\section{PCR and pyrosequencing}

Polymerase chain reaction was carried out on bisulphite converted genomic DNA using Platinum Taq polymerase (Invitrogen). Polymerase chain reaction cycling conditions were $94^{\circ} \mathrm{C}$ for $10 \mathrm{~min}$, followed by 45 cycles of $94^{\circ} \mathrm{C}$ for $60 \mathrm{~s}, 55^{\circ} \mathrm{C}$ for $60 \mathrm{~s}$ and $72^{\circ} \mathrm{C}$ for $40 \mathrm{~s}$, with a final $5 \mathrm{~min}$ extension at $72^{\circ} \mathrm{C}$. The biotinlabelled strand of the amplicon was isolated and pyrosequencing carried out using sequencing primers at the Genome Centre, Queen Mary University of London, London, UK. Primers sequences are shown in Supplementary information and Supplementary Table 3.

\section{Reverse transcription-PCR analysis}

First-strand cDNA synthesis was performed using random primers (Promega, Southampton, UK) with SuperScript III Reverse Transcriptase (Invitrogen). Polymerase chain reaction was carried out using $0.04 \mathrm{U}^{-1} \mathrm{l}^{-1}$ Kapa Taq (GRI, Essex, UK). Minus RT controls were routinely performed. Primers sequences are shown in Supplementary information and Supplementary Table 3.

\section{RESULTS}

\section{Global methylation of LINE-1 repetitive elements}

We first examined the global methylation status of 32 tumours from a bank of paediatric GCTs (Supplementary information and Supplementary Table 1) using the well-established strategy of analysing the LINE-1 repetitive element sequences via the combination of bisulphite and restriction analysis (COBRA) technique (Yang et al, 2004; Figure 1A-C). These sequences are normally heavily methylated, which is believed to be important to maintain them in a 'silent' state so that they cannot destabilise the genome (Belancio et al, 2010).

Consistent with studies in other cancers, the level of methylation of the LINE-1 elements in almost all GCT samples analysed was lower than that in controls (Figure 1D and E). Control samples averaged $68 \%$ methylation, whereas the level of methylation was significantly lower $(P<0.0001)$ in germinomas $(32 \%)$ and in YSTs $(42 \%)$. These differences were also seen between tumours and tissue-matched controls (Figure $1 \mathrm{~F}$ and $\mathrm{G}$ ). 
A

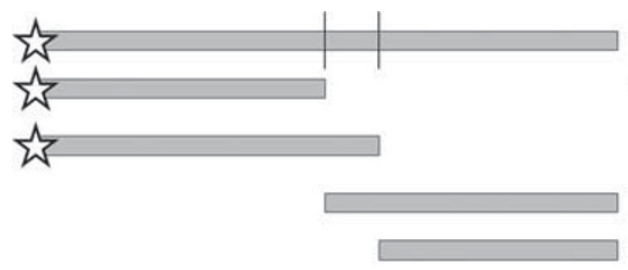

Unmethylated (421 bp)

Methylated

( 292 bp, 254 bp

$167 \mathrm{bp}, 129 \mathrm{bp}, 38 \mathrm{bp})$

B

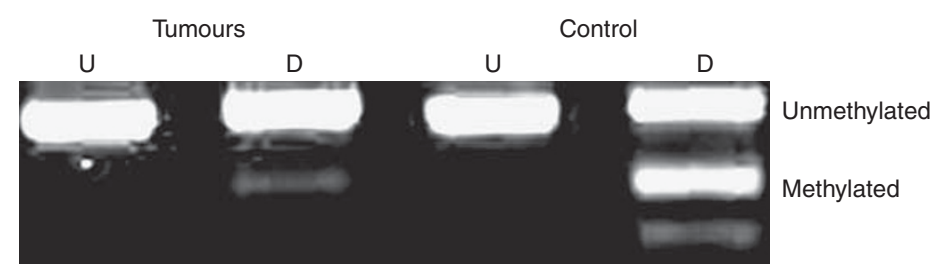

C

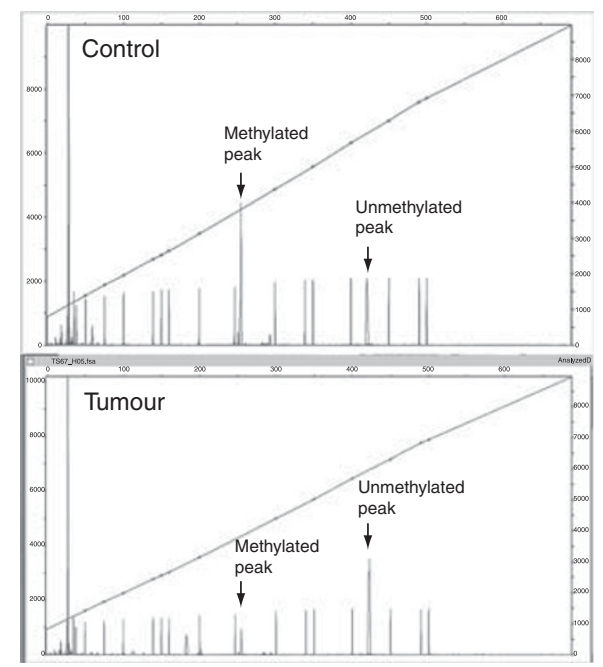

D

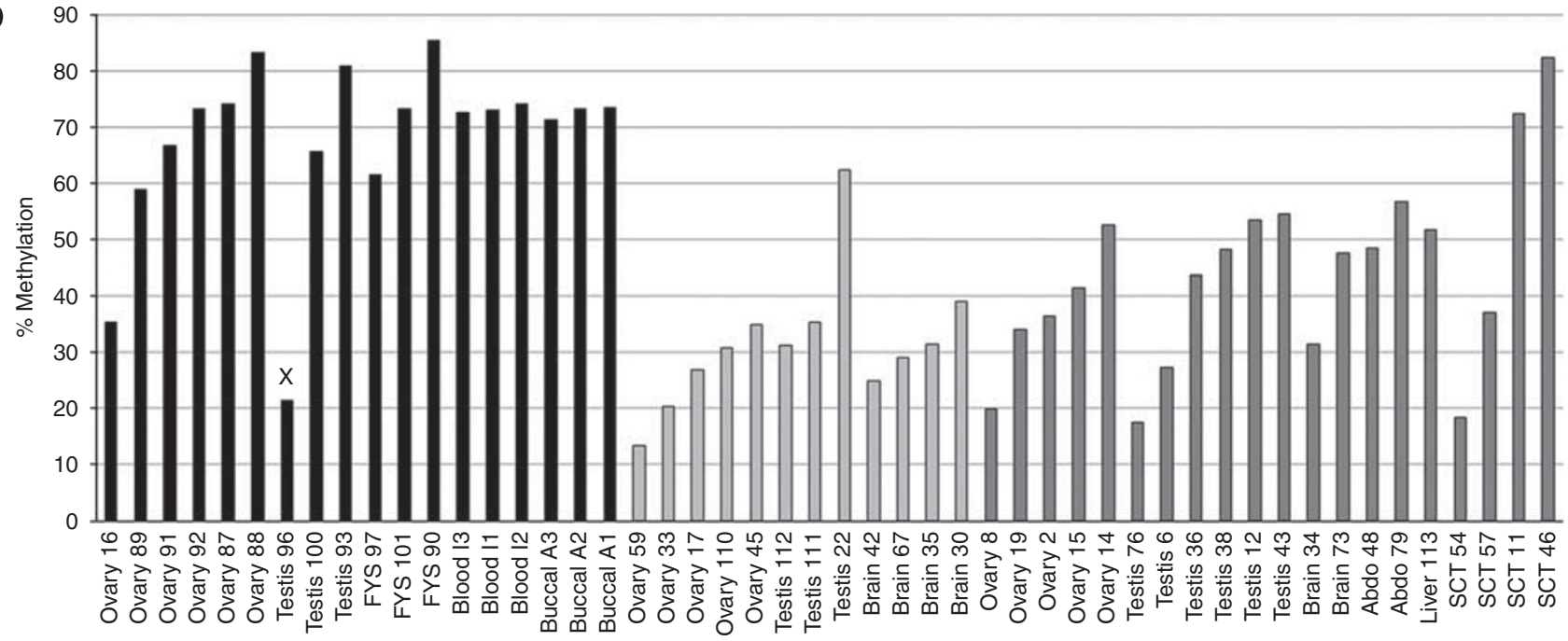

Samples
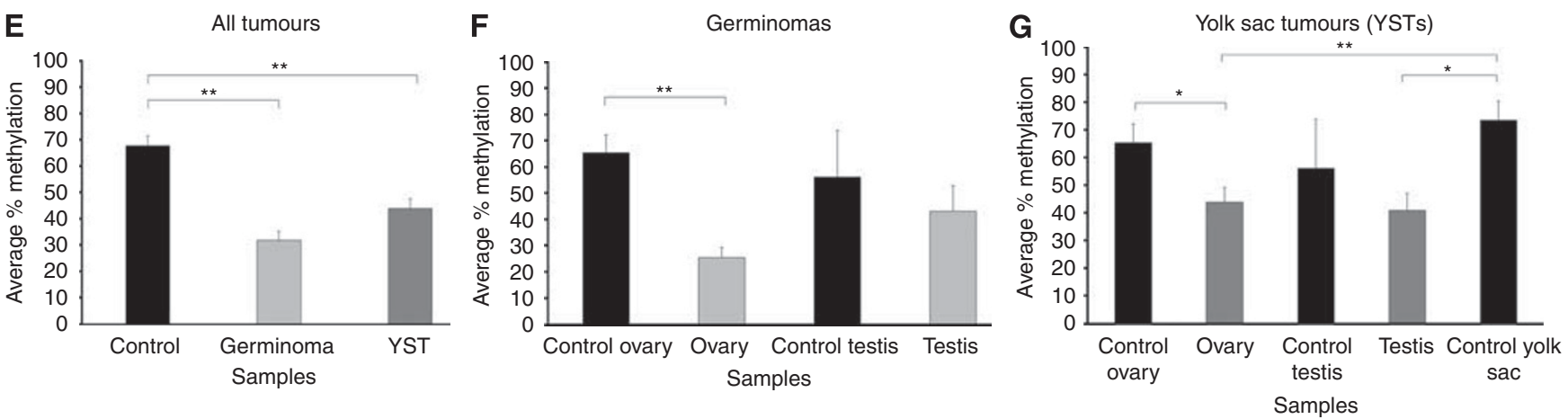

Figure I Combination of bisulphite and restriction analysis (COBRA) of LINE-I element methylation. (A) Diagram showing predicted digestion products. (B) Illustration of undigested $(U)$ and digested (D) PCR products from representative tumour and control samples. (C) Example of GeneScan data from a representative control and tumour samples. (D) Percentage methylation levels of LINE-I elements from individual samples as determined by GeneScan quantification. (E-G) Comparisons between tumour and control groups of samples showing that LINE-I elements are significantly hypomethylated in all tumour groups as compared with controls, except where testicular tumours were compared with normal testes samples. However, the latter appears to reflect one of the three testicular control samples having a very low methylation value $(x$ in $\mathbf{D})$. ${ }^{*} P<0.05,{ }^{*} * P<0.01$.

\section{Global methylation analysis of gene regulatory sequences}

We next used the GoldenGate beadchip system to assess the methylation status of gene regulatory regions. These beads carry an optimised set of 1505 CpG sites selected from 807 genes including known tumour suppressors, oncogenes and factors involved in processes such as DNA repair, cell cycle control, differentiation and apoptosis. Results were obtained for 15 
A

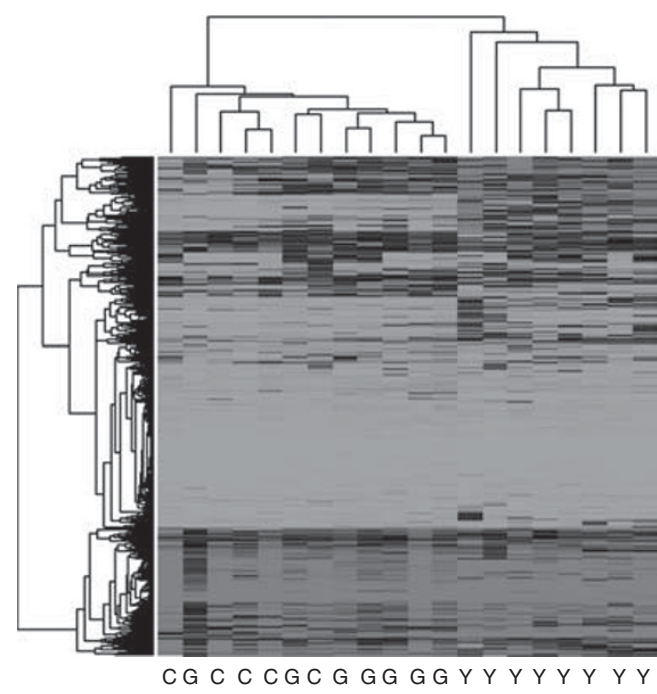

B

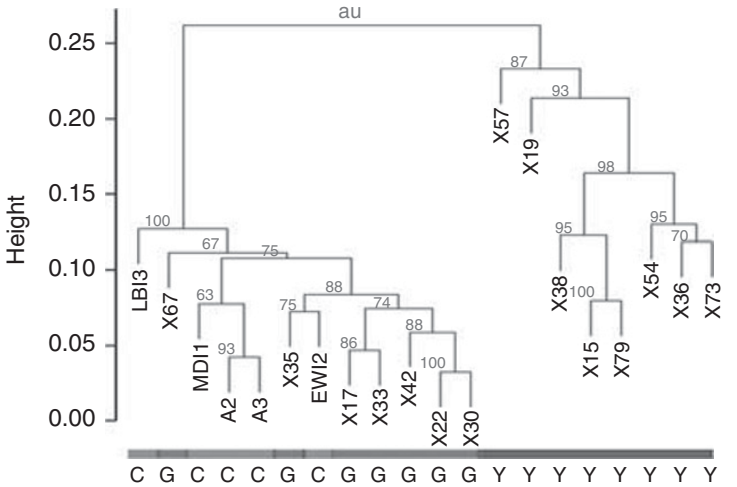

C

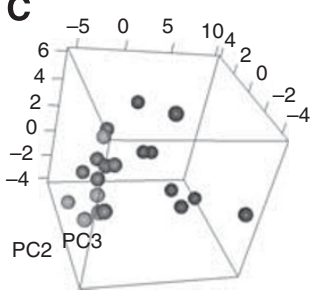

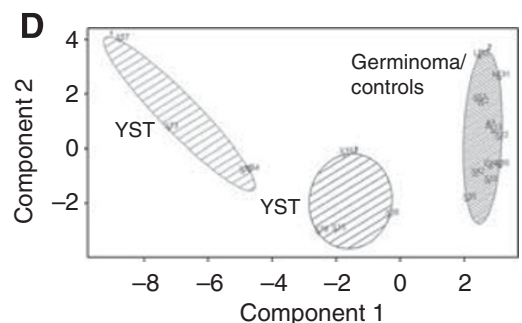

Figure 2 Cluster analysis of tumours according to methylation status. (A) Heat map showing that germinomas (G) cluster together with controls (C), whereas YSTs (Y) cluster separately, showing higher levels of methylation (red). (B) Bootstrapped hierarchical clustering using the R package pvclust (Suzuki and Shimodaira, 2006). Subgroups with an approximate unbiased $P$-values of $<0.05$ were significant. $(\mathbf{C})$ The observed clustering patterns were assessed using principal component analysis and $k$ means analysis. Yolk sac tumours are shown in blue, germinomas in red and controls in green. (D) Plot shows subgroup members selected by $k$ means analysis plotted against the first two principal components. The optimal number of clusters for $k$ means analysis was assessed using Scree plots. Differentially methylated loci between subgroups were identified using Mann-Whitney U-tests, with an adjusted P-value $<0.05$ after Benjamini-Hochberg false discovery rate correction for multiple testing. The colour reproduction of this figure is available at the British Journal of Cancer online.

tumours (seven germinomas and eight YSTs) and five control samples from healthy individuals (buccal cells from two adult male subjects and peripheral blood from three infants) (Supplementary Tables 1 and 2). Unsupervised hierarchical clustering grouped the germinomas and controls together, whereas YSTs formed an independent cluster exhibiting a generally more methylated status (Figure $2 \mathrm{~A}$ and $\mathrm{B}$ ). Using three-dimensional principle component analysis, YSTs again formed a separate group from the germinomas and controls, which formed a single group (Figure 2C). Even when we used $k$-means analysis of the 20 samples (a preceding Scree plot had determined that three clusters were optimal) germinomas remained clustered together with the control samples and it was the YSTs that were separated into two distinct groups (Figure 2D).

\section{YSTs but not germinomas exhibit widespread hypermethylation of gene regulatory sequences}

To describe differences between $\beta$-values (delta $\beta$-value) that were considered 'significant', we analysed an additional, independent cohort of nine germinomas and 11 YSTs (Supplementary Tables 1 and 2). This revealed that the majority of delta $\beta$-values $>0.3$ were consistent between the two tumour subtypes in both cohorts of samples. We therefore used this delta $\beta$-value to determine significant differences in methylation. It is worth noting that this value is among the more stringent values used in previous studies (Martin-Subero et al, 2009; Richter et al, 2009; Ang et al, 2010).

Of the genes included on the GoldenGate array, 131 (16\%) were significantly more methylated in YSTs than in germinomas (Supplementary Table 1; X-chromosome genes were excluded as they would normally differ between male and female subjects due to X-chromosome inactivation.). Importantly, we also determined which genes were hypermethylated or hypomethylated in GCTs as compared with 'normal' control tissues. Overall, we found little evidence of hypomethylation. In germinomas, only 4 out of 807 genes $(0.5 \%$ of genes tested) were significantly less methylated than controls and only 13 out of 807 genes were hypomethylated in YSTs. Indeed, only one gene, $C D 86$, was reproducibly hypermethylated in germinomas and there is no evidence to suggest that this cell surface marker can function as a tumour suppressor.

Therefore, comparison to normal control tissues allowed us to show that the germinomas in our study have a normal level of methylation of gene regulatory regions, not 'as good as devoid of DNA methylation' as was concluded by Lind et al (2007) with respect to seminomatous GCTs. Such a lack of hypermethylation makes germinomas a very unusual tumour type compared with the other classes of tumour analysed to date.

\section{Many potential tumour suppressor genes are methylated in YSTs}

In our initial array analysis, 85 out of 807 genes (10.5\%) were hypermethylated in YSTs, but not germinomas (Supplementary Table 2; top 25 shown in Figure $3 \mathrm{~A}$ ). In this study, the genes identified to be specifically hypermethylated in paediatric YSTs were highly reproducible. In the second cohort of GCTs analysed, a similar number of genes were hypermethylated (104 out of 807, $12.8 \%), 71$ of which were the same genes identified in the first cohort, with three genes appearing in the top five (as ranked by delta $\beta$-value) in both cohorts (Figure 3B). Indeed, analysis of each tumour for the methylation status of the 85 genes initially identified showed that 27 of these genes were hypermethylated in $\geqslant 85 \%$ of tumours from both cohorts (Figure 3C). Hence, it appears that the significant majority of YSTs exhibit a very similar 'methylator' phenotype.

These hypermethylated genes included several that others have shown to be highly methylated in adult testicular non-seminomas. Previous studies used a candidate gene approach to identify nine genes, from a total of 39 studied, that were frequently methylated in non-seminomatous adult testicular GCTs, especially in YSTs 

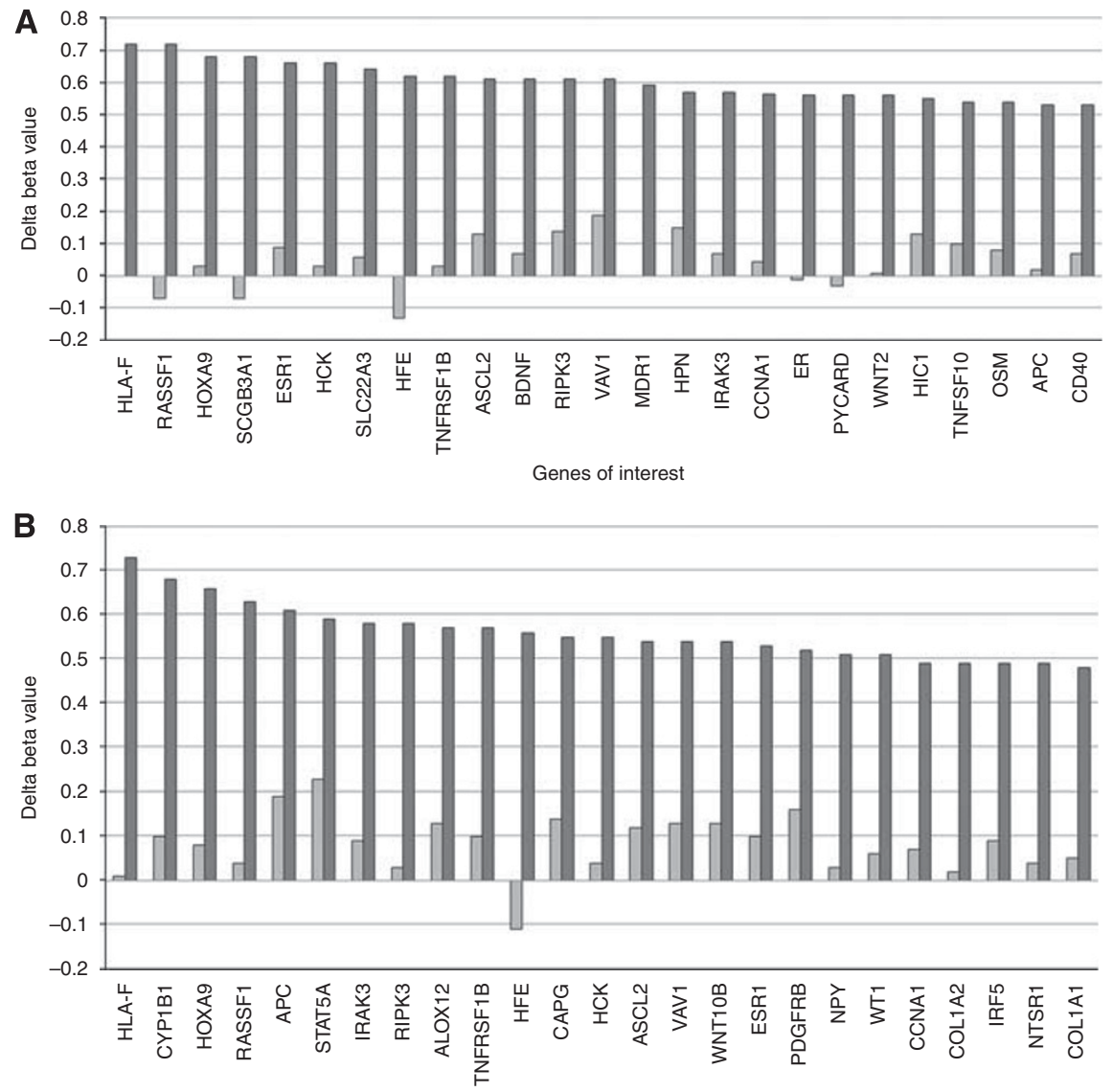

Genes of interest

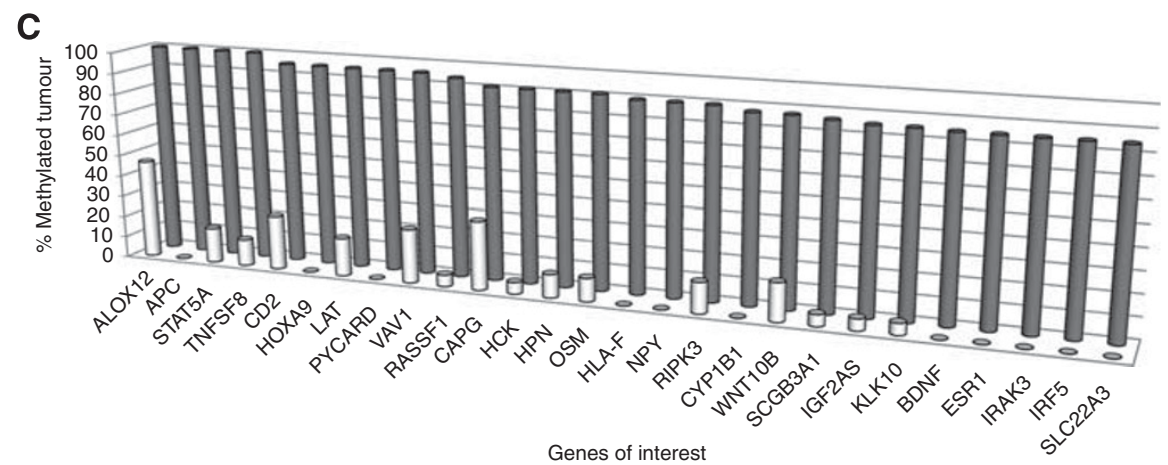

Figure 3 Graphical representation of the 25 most differentially methylated genes in YSTs. Bars represent average difference of methylation to controls for each gene in either YSTs (dark bars) or germinomas (pale bars) in the first (A) and second (B) cohorts of tumours analysed. (C) The percentage of tumours across both cohorts analysed in which each gene was hypermethylated in either YSTs (dark bars) or germinomas (pale bars).

(Koul et al, 2002, 2004; Smith-Sorensen et al, 2002; Honorio et al, 2003; Manton et al, 2005; Lind et al, 2006, 2007). Of these previously identified genes, we found that five (RASSF1A, HOXA9, $S C G B 3 A 1, H I C 1, A P C)$ of the nine included in our initial array analysis were also significantly more methylated in YSTs than in germinomas.

Previously, RASSF1A, HOXA9, SCGB3A1, HIC1 and APC had been shown to be hypermethylated in $100 \%$ of YSTs analysed (Honorio et al, 2003; Rathi et al, 2003; Koul et al, 2004; Lind et al, 2006; Brieger et al, 2010). However, we found only one of these genes hypermethylated in all YST samples from both cohorts of tumours analysed (Figure 3C). This was largely due to the presence of a single YST in the second cohort that lacked the methylator phenotype (approximately $74 \%$ of the genes that were hypermethylated in most other YSTs exhibited no significant hypermethylation in this tumour). To gain a clear indication of those genes most strongly associated with the methylator phenotype, we next excluded the single YST lacking the methylator phenotype. We found three genes hypermethylated in all of these (HOXA9, APC, PYCARD), which were methylated in less than $25 \%$ of germinomas and a further 30 genes hypermethylated in over $80 \%$ of the YST samples (14 of these genes were not methylated in a single germinoma and 16 were methylated in $<25 \%$ of germinomas; Table 1).

Among the genes selectively methylated in YSTs, many have been previously implicated as tumour suppressors (Table 2). However, rather surprisingly, of the 'top 14' most frequently reported genes that are hypermethylated in human cancers 
(Cheung et al, 2009), all of which were included in our array analysis, only RASSF1A, APC and ESR 1 were methylated in the majority of YSTs and almost none were methylated in germinomas. Even more striking is the fact that a recent analysis of gliomas exhibiting a 'methylator' phenotype showed 12 of these 14 genes to be hypermethylated, but APC and ESR 1 are the very genes that did not show hypermethylation in these gliomas (Noushmehr et al, 2010). Our findings therefore suggest that the vast majority of YSTs exhibit a strong methylator phenotype, but that this is quite a different methylation signature to that seen in other tumour types (Weisenberger et al, 2006; Shen et al, 2007), suggesting a different underlying mechanism.

\section{Validation of methylation array data}

Pyrosequencing of bisulphite-treated DNA was used to validate the data from the GoldenGate arrays, which also extended the number of CpGs analysed. We selected PYCARD for this purpose as, although this gene was significantly hypermethylated in almost all YSTs and, as discussed below, this was reflected in a difference in its expression between YSTs and germinomas, the difference in the level of methylation between germinomas and YSTs was moderate. PYCARD therefore represented a stringent validation test of the methylation arrays. Owing to the limited availability of the tumour DNA samples, this analysis was carried out only on five samples in duplicate, which showed that the entire protocol was highly reproducible (Figure 4A).
Pyrosequencing was carried out on the proximal promoter region of PYCARD from a position $-234 \mathrm{bp}$ proximal to the transcription start site. The amplified sequence was $100 \mathrm{bp}$ including six CpGs, one of which (at position -151) was also included in the arrays. Comparison of the methylation values obtained for this single $\mathrm{CpG}$ between pyrosequencing and the original arrays showed a strong correlation between the two techniques (Figure 4B). Pyrosequencing also revealed that CpGs adjacent to this $\mathrm{CpG}$ shared a similar methylation status (Figure 4A). These data validated the difference in methylation of PYCARD between germinomas and YSTs and showed that this difference was shared with other, nearby CpGs.

\section{Relationship between methylation and gene expression}

If differences in gene methylation are of biological significance to the pathogenesis of GCTs, it seems probable that they must affect the expression of those genes. In the previous studies of methylated genes in adult testicular GCTs, only one gene, RASSF1A, which was methylated in a large proportion of nonseminomatous tumours and unmethylated in most seminomatous tumours, exhibited an expression pattern that correlated with its methylation status between the two tumour subtypes (Koul et al, 2002). To determine if the methylation we saw correlated with gene expression in the tumour cells, we compared our data to the expression array analysis previously reported for this same bank of tumours (Palmer et al, 2008). Overall, the majority of hyper-

Table I Genes hypermethylated in more than $80 \%$ of YST samples analysed by GoldenGate array

Genes hypermethylated in more than $80 \%$ of YST samples, and in $<25 \%$ of germinoma samples in the methylation array

APC, ASCL2, BDNF, CCNAI, CD2, CYPIBI, ESRI, HCK, HFE, HLA-F, HOXA9, HPN, HS3ST2, IGF2AS, IRAK3, IRF5, KLKIO, LAT, NPY, NTSRI, OSM, PDGFRB, PYCARD, RASSFI, RIPK3, SCGB3AI, SLC22A3, STAT5A, TALI, TNFSF8, VAVI, WNTI, WNTIOB

Abbreviations: YST = yolk sac tum. Genes in bold were hypermethylated in all YSTs exhibiting the 'methylator' phenotype

Table 2 List of genes that have previously been implicated as tumour suppressors among the 85 genes hypermethylated in YSTs

\begin{tabular}{|c|c|c|}
\hline Genes & Tumour type & Reference \\
\hline RASSFI & Testicular germ cell tumour; nasopharyngeal carcinoma & $\begin{array}{l}\text { Honorio et al (2003); Koul et al (2004); Lind et al (2006); } \\
\text { Wang et al (2009) }\end{array}$ \\
\hline HOXA9 & Breast cancer, testicular cancer & Lind et al (2006); Gilbert et al (2010) \\
\hline SCGB3Al & Breast cell lines; mouse transformed Clara cells; testicular cancer & Krop et al (2005); Lind et al (2006); Tomita et al (2009) \\
\hline ESRI & Squamous cell carcinoma & Zhai et al (2010) \\
\hline SLC22A3 & Prostate cancer & Tomlins et al (2007) \\
\hline PYCARD/ASC/TMS & Leukemia-derived cell lines; colon adenocarcinoma and stomach cancer cell lines & Calvanese et al (2008); Mhyre et al (2009); Motani et al (20l0) \\
\hline WNT2 & Colorectal cancer & Shi et al (2007) \\
\hline $\mathrm{HICl}$ & Paediatric neoplasm; head and neck squamous cell carcinoma & Rathi et al (2003); Koul et al (2004); Brieger et al (2010) \\
\hline$A P C$ & Testicular germ cell tumour; invasive ductal carcinoma & Honorio et al (2003); Cho et al (20l0) \\
\hline IRF5 & Gastric cancer & Yamashita et al (2010) \\
\hline SLIT2 & Lung cancer; glioma cell & Tseng et al (20l0); Yiin et al (2009) \\
\hline TFAP2C & Human extravillious throphoblast cell; breast adenocarcinoma & Li et al (2006); Kotani et al (2009) \\
\hline SLC5A8 & Head and neck squamous cell carcinoma & Bennett et al (2009) \\
\hline CASP8 & Neuroblastoma & Hoebeeck et al (2009) \\
\hline FES & Mouse mast cells; colorectal Cancer & Shaffer and Smithgall (2009); Voisset et al (2010) \\
\hline WTI & Ovarian clear-cell adenocarcinoma; gastric, lung, fibrosarcoma, glioblastoma & Kaneuchi et al (2005); Tatsumi et al (2008) \\
\hline $\mathrm{CDH} / 3$ & Pituitary adenomas & Qian et al (2007); Andreeva and Kutuzov (2010) \\
\hline$K L K I O$ & Non-small-cell lung cancer & Zhang et al (2010) \\
\hline LTB4R & Colon cancer & Ihara et al (2007) \\
\hline THYI & Nasopharyngeal carcinoma & Lung et al (2010) \\
\hline TNFRSFIOC & Prostate carcinoma & Hornstein et al (2008) \\
\hline COLIA2 & Colorectal cancer & Sengupta et al (2003) \\
\hline SIOOA4 & Pancreatic cancer cell lines & Tabata et al (2009) \\
\hline DCC & Colon cancer cells & Rodrigues et al (2007) \\
\hline PTPRO & Lung cancer & Motiwala et al (2004) \\
\hline TPEF & Colon, bladder, prostate cancer & Liang et al (2010) \\
\hline
\end{tabular}

Abbreviation: YST = yolk sac tum. Additional references in Supplementary information. 

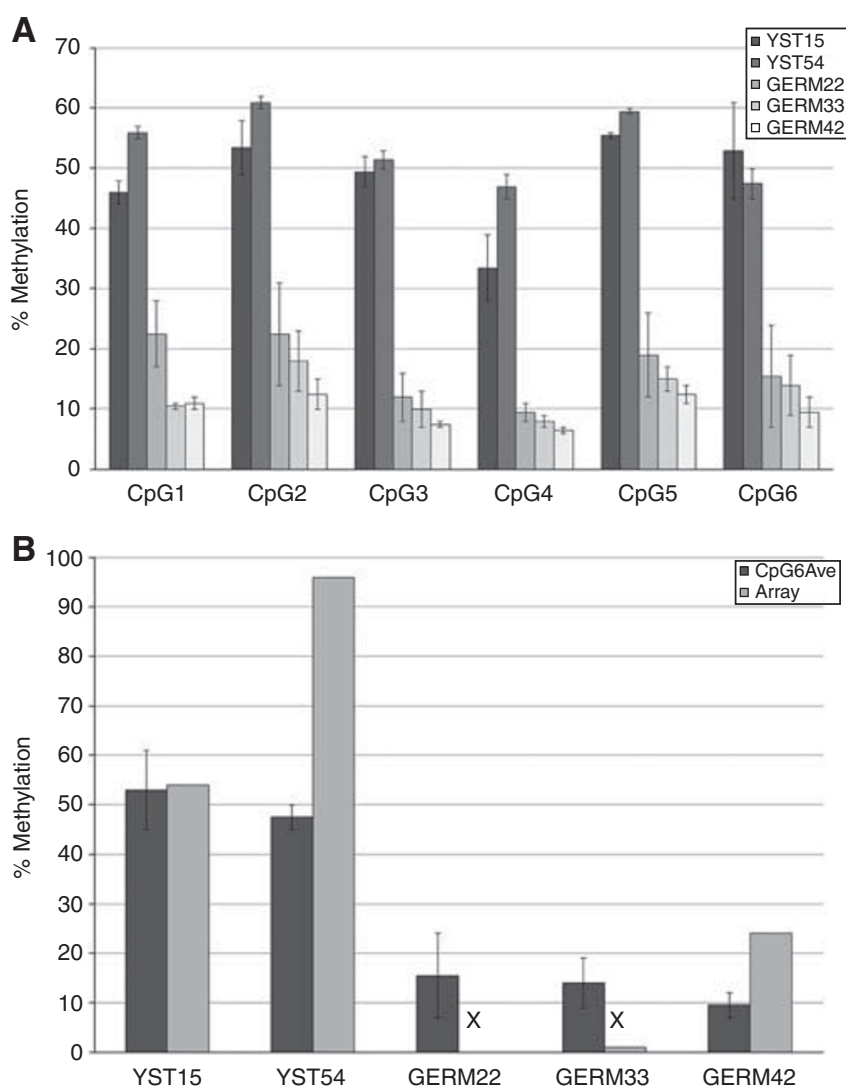

Figure 4 Pyrosequence of the $C P G$ island of the PYCARD gene from selected tumour samples. (A) Graph showing percentage methylation of two YST and three germinoma samples at the six CpG positions included in the region of pyrosequencing for the PYCARD gene (I00 bp between positions -234 and -135 proximal to the start of transcription). The YST samples show clear hypermethylation when compared with the germinoma samples. (B) Comparison between the percentage methylation at the sixth $\mathrm{CpG}(-|5|)$ in the five tumours shown in $(\mathbf{A})$, as determined from either the pyrosequencing (dark bars) or from the methylation array (pale bars). This shows strong correlation between the array and pyrosequencing results and also suggests that the pyrosequencing gives more quantitative values at lower levels of methylation where these are below the level detectable in the array (arrow heads). Bars show the range for the two samples. methylated genes showed no significant difference in expression (taken as an LOD score or B-statistic value of 3 or more). This may not be surprising, as absence of methylation is not the only prerequisite for a gene to be expressed. However, among the genes that we identified as methylated in YSTs, but not in germinomas, eight were selectively expressed in germinomas, whereas only one was selectively expressed in YSTs (Table 3).

Among the genes methylated in YSTs and selectively expressed in germinomas, TFAP2C, PYCARD, CD2, CASP8 (Caspase 8), $E V I 2 A$ and $H L A-F$ were very biased in both methylation and expression, with LOD scores for the difference in expression $>4$ (Palmer et al, 2008) and hypermethylation in $>75 \%$ of YSTs and in $25 \%$ or fewer germinomas (except TFAP2C, which was only hypermethylated in $63 \%$ of YSTs, but in no germinomas) (Figure 3C). It is striking that this list does not include the genes previously implicated by methylation in GCTs, such as HOX9A or RASSF1A, but instead identifies six new genes as the best candidates for a role of DNA methylation in GCT biology. Of these, CASP8 and PYCARD are of particular interest as they are known to be associated with apoptosis.

\section{Cause of hypermethylation in YSTs}

In other cancers, changes in specific components of the epigenetic machinery have been shown to cause hypermethylation. EZH2 and SUZ12, components of the polycomb PRC2 complex, have been implicated in several types of cancer (Chen et al, 2010; Karanikolas et al, 2010; Martin-Perez et al, 2010). Also, overexpression of the DNA methyltransferase, DNMT3B, was identified in lung and breast cancer cell lines (Beaulieu et al, 2002) and depletion of $D N M T 3 B$ expression in breast cancer cell line was shown to activate the methylated RASSF1 (Wang et al, 2006); therefore, we analysed the expression of these factors by qRT-PCR.

Although we had access to only a small number of RNA samples from the same tumours analysed for their methylation status, our data did reveal a significant difference between germinomas and YSTs in the level of expression of DNMT3B (Figure 5), but not EZH2 or SUZ12 (data not shown). DNMT3B was generally expressed at levels 4-16-fold greater in the YST samples analysed compared with the germinoma samples. Indeed, analysis of the array data on the same cohort of GCTs (Palmer et al, 2008) revealed that DNMT3B was more strongly expressed in YSTs than in germinomas (LOD scores of 3.36 and 6.7, respectively,

Table 3 Comparison between methylation status and expression levels for genes in which these show significant correlation

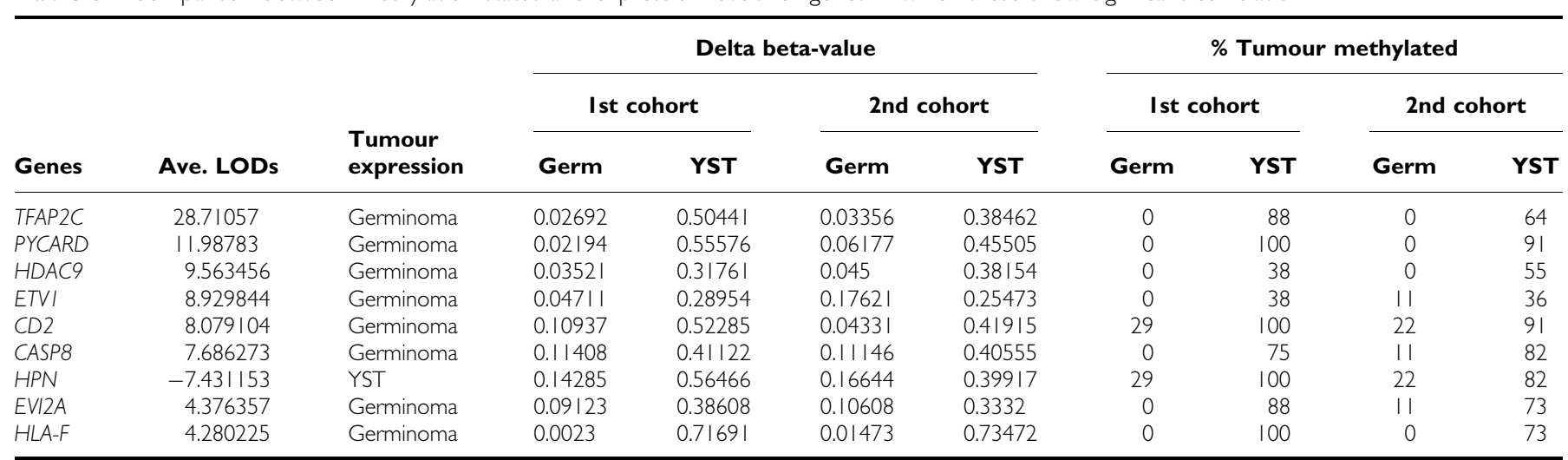

Abbreviations: GCT = germ cell tumours; $L O D=$ logarithm of odds; YST = yolk sac tum. aveLODS represents the degree to which these genes are expressed at higher levels in germinomas than in YSTs (from Palmer et al (2008)). Methylation status is shown as the delta beta-value for difference in methylation between germinomas and YSTs in the two cohorts of GCTs analysed, and as a percentage of tumours in which the gene was significantly hypermethylated. 


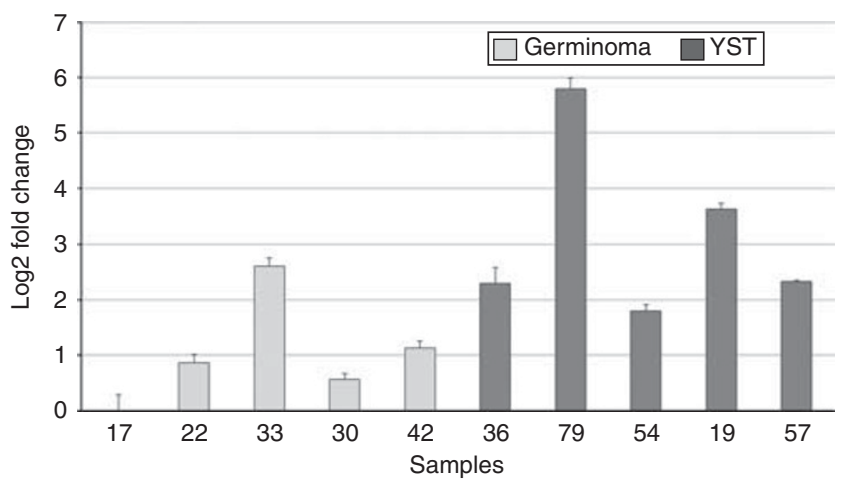

Figure 5 Quantitative RT-PCR analysis of DNMT3B expression. Graph showing the expression level of DNMT3B in five germinomas (pale bars) and five YST samples (dark bars). Error bars show standard deviation.

$P=0.0006)$. DNMT3B overexpression therefore provides a strong candidate to explain the methylator phenotype seen in those YSTs.

\section{DISCUSSION}

Previous studies have identified a small number of genes that are hypermethylated in adult testicular GCTs, with non-seminomatous tumours exhibiting much higher levels of methylation than their seminomatous counterparts. In this study, we have performed the first array-based analysis of the methylation status of GCT genomes. In particular, we have studied paediatric tumour samples from a range of gonadal and extragonadal locations. This has revealed that, while there is global hypomethylation of repetitive elements in both germinomas and YSTs and in GCTs from all anatomical locations, there is little hypomethylation of gene regulatory sequences. Germinomas also show little hypermethylation, whereas many genes are hypermethylated in YSTs regardless of tumours site, patient age or sex. The set of genes hypermethylated in YSTs was very consistent across two independent cohorts of tumour samples and so identifies a large number of candidate tumour suppressors for future functional analysis.

\section{The role of methylation in GCTs}

Our study agrees with the recent consensus that reduced methylation of repetitive elements is not reflected in a general lack of methylation of gene regulatory elements (De Smet and Loriot, 2010). Hence, any contribution of global hypomethylation is likely to be through its effects on repeat elements. Two general models have been proposed. In the first, lack of methylation of repeat elements might mobilise them, resulting in genomic instability (Schulz et al, 2006), as was seen in a mouse model in which global methylation was disrupted owing to a hypomorphic mutation in Dnmt1 (Gaudet et al, 2003; Howard et al, 2008). In the second model, activation of transcription of these elements might be associated with an increase in transcription of adjacent genes (Cruickshanks and Tufarelli, 2009; Weber et al, 2010). Given the general hypomethylation of LINE-1 elements in GCTs, the potential mechanism by which this may affect tumour development is worthy of further investigation.

As 131 of 807 genes analysed were hypermethylated in YSTs, it seems premature to assume that any one of these genes might have a significant role in the tumours' aetiology. Indeed, earlier studies have not generally shown whether differences in methylation in GCTs correlated with any difference in the expression of those genes (Lind et al, 2007). It is clear from our data that the majority of the genes that are differentially methylated between germinomas and YSTs are not differentially expressed (Palmer et al, 2008). This provides a much smaller number of genes in which methylation status correlates with expression levels, which are therefore more likely to have a role in GCT pathogenesis. Although we found methylation of five of the previously identified genes that were known to be hypermethylated in YSTs, none of these exhibited a significant difference in expression between the two tumour subtypes.

Among the six genes where methylation state corresponded with expression, CASP8 and PYCARD were of particular note as they both act in the same apoptotic pathway. Caspase 8 is critical for death receptor-induced, extrinsic apoptosis (triggered by the death ligand TRAIL/TNFSF10 and other tumour necrosis superfamily factors (TNFSFs)). However, Caspase 8 is also central to cell death induced by chemotherapeutic agents in a number of cancer cell types (Kim et al, 2001). Moreover, Caspase 8 is silenced by methylation in several other classes of cancer (Fulda, 2009). Similarly, PYCARD (also known as ASC/TMS1) is repressed by methylation in a range of tumours and has been implicated in several antitumour activities (Kim et al, 2001; McConnell and Vertino, 2004). In particular, PYCARD not only interacts with Caspase 8, but also can induce Caspase 8-dependent apoptosis (Masumoto et al, 2003), and it has also been implicated in apoptosis induced by a wide range of chemotherapeutic agents (Masumoto et al, 1999).

It is striking that among the tumour necrosis factor superfamily members and their receptors, six of the seven members represented on the arrays were selectively methylated in YSTs. These were TNFSF8 and TNFSF10 (the TRAIL ligand), and the TNFSF receptors, TNFRSF10A, 10C and 10D (three of the four death receptors for the TRAIL ligand) and TNFRSF1B (one of the other three death receptors acting via Caspase 8) (Guicciardi and Gores, 2009). Our data therefore provide a strong indication that methylation of genes associated with Caspase 8-dependent cell death might explain the relative resistance of YSTs to therapyinduced cell death (Fujimaki, 2009; Fulda, 2009). Therapeutic trials to activate CASP8 that had been silenced by methylation have already taken place for other tumour types with some promising results (reviewed by Fulda, 2009).

\section{Relationship between the methylation status of germinomas and YSTs}

Our data are consistent with a model in which the initiation of GCTs, such as germinomas, does not involve major changes in the methylation of gene regulatory elements, but subsequent methylation changes are then associated with the transition to a YST-like phenotype. Whether these changes are the cause or the result of this alteration in tumour phenotype is yet to be determined. This stepwise model may explain the occurrence of GCTs containing a mixture of seminoma and YST components (Looijenga, 2009) and the rare examples of seminomatous tumours that recur as a YST after therapy (Wong et al, 2010). Indeed, a recent report described a brain tumour that appeared to transform from a germinoma to a non-germinoma phenotype, even before treatment (Wong et al, 2010). A model in which all types of adult testicular GCTs, including seminomatous and non-seminomatous tumours, arise from a common carcinoma in situ (CIS) precursor lesion was proposed by Skakkebaek et al (1987).

\section{Mechanism of YST methylator phenotype}

The substantial difference in methylation between germinomas and most YSTs suggests that a fundamental mechanism has been disrupted. Although it remains to be experimentally tested, our observation that $D N M T 3 B$ is expressed at significantly higher levels in YSTs than in germinomas provides a possible explanation for this difference and, as YSTs exhibit a more aggressive 
natural history than germinomas, a target for potential therapy. Consistent with this suggestion, we found that 11 of about 70 genes recently identified as targets for DNMT3B1 (Choi et al, 2011) are among the genes methylated in our cohort of YSTs, whereas only two of the DNMT3A1-specific targets were methylated (all were present on our arrays). In addition, 23 of the genes that are targeted by both DNMTs were also methylated in the YST samples.

Interestingly, a recent study comparing microRNA expression profiles between paediatric YSTs and germinomas identified significant upregulation of all members of the miR-29 family (miR-29a, miR-29b and miR-29c) in germinomas $(P=0.0001)$ (Murray et al, 2010), which correlates with the level of expression of DNMT3A and DNMT3B in the two subtypes of GCT. MicroRNA$29 \mathrm{~b}$ has been shown to target and knock down expression of both DNMT3A and DNMT3B in cancer cells, with a consequent decrease in genome-wide methylation (Fabbri et al, 2007; Garzon et al, 2009). These observations therefore suggest a mechanism whereby relatively low levels of the miR-29 family members in YSTs may result in de-repression of $D N M T 3 B$, allowing the methylator phenotype to occur in this GCT subtype.

In conclusion, our data indicate that the methylator phenotype is a feature of the YSTs irrespective of anatomical location, patient age or sex. The gene targets of this methylation provide candidates for further analysis as potential tumour suppressors, especially compo- nents of Caspase 8-dependent apoptosis. Most importantly, our initial analysis suggests that the methylator phenotype, which is associated with the more aggressive subtype of tumour, the YST, is also associated with increased expression of DNMT3B. It will now be important to determine directly whether it is DNMT3B itself or another factor(s) that is the cause of the altered methylation.

\section{ACKNOWLEDGEMENTS}

JNJ was supported by Ali's Dream and Charlie's Challenge; DAM by Malaysian Ministry of Higher Education; VA by the Samantha Dickson Brain Tumour Trust; CLT by an MRC studentship and the Nottingham Children's Brain Tumour Research Centre; RDP and MJM by MRC Clinical Research Training Fellowships; and ECS by the Katie Trust. This work was also supported by a grant from the Association for International Cancer Research.

\section{Conflict of interest}

The authors declare no conflict of interest.

Supplementary Information accompanies the paper on British Journal of Cancer website (http://www.nature.com/bjc)

\section{REFERENCES}

Andreeva AV, Kutuzov MA (2010) Cadherin 13 in cancer. Genes Chromosomes Cancer 49: 775-790

Ang PW, Loh M, Liem N, Lim PL, Grieu F, Vaithilingam A, Platell C, Yong WP, Iacopetta B, Soong R (2010) Comprehensive profiling of DNA methylation in colorectal cancer reveals subgroups with distinct clinicopathological and molecular features. BMC Cancer 10: 227

Beaulieu N, Morin S, Chute IC, Robert MF, Nguyen H, MacLeod AR (2002) An essential role for DNA methyltransferase DNMT3B in cancer cell survival. J Biol Chem 277: 28176-28181

Belancio VP, Roy-Engel AM, Deininger PL (2010) All y'all need to know 'bout retroelements in cancer. Semin Cancer Biol 20: 200-210

Benjamini Y, Hochberg Y (1995) Controlling the false discovery rate - a practical and powerful approach to multiple testing. J R Statist Soc Ser B 57: $289-300$

Bennett KL, Romigh T, Eng C (2009) Disruption of transforming growth factor-beta signaling by five frequently methylated genes leads to head and neck squamous cell carcinoma pathogenesis. Cancer Res 69: 9301-9305

Bibikova M, Lin Z, Zhou L, Chudin E, Garcia EW, Wu B, Doucet D, Thomas NJ, Wang Y, Vollmer E, Goldmann T, Seifart C, Jiang W, Barker DL, Chee MS, Floros J, Fan JB (2006) High-throughput DNA methylation profiling using universal bead arrays. Genome Res 16: 383-393

Brieger J, Pongsapich W, Mann SA, Hedrich J, Fruth K, Pogozelski B, Mann WJ (2010) Demethylation treatment restores hicl expression and impairs aggressiveness of head and neck squamous cell carcinoma. Oral Oncol 46: $678-683$

Calvanese V, Horrillo A, Hmadcha A, Suarez-Alvarez B, Fernandez AF, Lara E, Casado S, Menendez P, Bueno C, Garcia-Castro J, Rubio R, Lapunzina P, Alaminos M, Borghese L, Terstegge S, Harrison NJ, Moore HD, Brüstle O, Lopez-Larrea C, Andrews PW, Soria B, Esteller M, Fraga MF (2008) Cancer genes hypermethylated in human embryonic stem cells. PLoS One 3: e3294

Chen Y, Xie D, Yin Li W, Man Cheung C, Yao H, Chan CY, Chan CY, Xu FP, Liu YH, Sung JJ, Kung HF (2010) RNAi targeting EZH2 inhibits tumor growth and liver metastasis of pancreatic cancer in vivo. Cancer Lett 297: $109-116$

Cheung HH, Lee TL, Rennert OM, Chan WY (2009) DNA methylation of cancer genome. Birth Defects Res Part C 87: 335-350

Cho YH, Yazici H, Wu HC, Terry MB, Gonzalez K, Qu M, Dalay N, Santella RM (2010) Aberrant promoter hypermethylation and genomic hypomethylation in tumor, adjacent normal tissues and blood from breast cancer patients. Anticancer Res 30: 2489-2496
Choi SH, Heo K, Byun HM, An W, Lu W, Yang AS (2011) Identification of preferential target sites for human DNA methyltransferases. Nucleic Acids Res 39(1): 104-118

Cruickshanks HA, Tufarelli C (2009) Isolation of cancer-specific chimeric transcripts induced by hypomethylation of the LINE-1 antisense promoter. Genomics 94: 397-406

De Smet C, Loriot A (2010) DNA hypomethylation in cancer epigenetic scars of a neoplastic journey. Epigenetics 5: 206-213

Dunning MJ, Smith ML, Ritchie ME, Tavare S (2007) Beadarray: R classes and methods for Illumina bead-based data. Bioinformatics 23: 2183-2184

Fabbri M, Garzon R, Cimmino A, Liu Z, Zanesi N, Callegari E, Liu S, Alder H, Costinean S, Fernandez-Cymering C, Volinia S, Guler G, Morrison CD, Chan KK, Marcucci G, Calin GA, Huebner K, Croce CM (2007) MicroRNA-29 family reverts aberrant methylation in lung cancer by targeting DNA methyltransferases 3A and 3B. Proc Natl Acad Sci USA 104: $15805-15810$

Feinberg AP, Tycko B (2004) The history of cancer epigenetics. Nat Rev Cancer 4: $143-153$

Feinberg AP, Vogelstein B (1983) Hypomethylation distinguishes genes of some human cancers from their normal counterparts. Nature 301: 89-92

Fujimaki T (2009) Central nervous system germ cell tumors: classification, clinical features, and treatment with a historical overview. J Child Neurol 24: $1439-1445$

Fulda S (2009) Caspase-8 in cancer biology and therapy. Cancer Lett 281: 128 - 133 Garzon R, Liu S, Fabbri M, Liu Z, Heaphy CE, Callegari E, Schwind S, Pang J, Yu J, Muthusamy N, Havelange V, Volinia S, Blum W, Rush LJ, Perrotti D, Andreeff M, Bloomfield CD, Byrd JC, Chan K, Wu LC, Croce CM, Marcucci G (2009) MicroRNA-29b induces global DNA hypomethylation and tumor suppressor gene reexpression in acute myeloid leukemia by targeting directly DNMT3A and 3B and indirectly DNMT1. Blood 113: 6411-6418

Gaudet F, Hodgson JG, Eden A, Jackson-Grusby L, Dausman J, Gray JW, Leonhardt H, Jaenisch R (2003) Induction of tumors in mice by genomic hypomethylation. Science 300: 489-492

Gilbert PM, Mouw JK, Unger MA, Lakins JN, Gbegnon MK, Clemmer VB, Benezra M, Licht JD, Boudreau NJ, Tsai KK, Welm AL, Feldman MD, Weber BL, Weaver VM (2010) HOXA9 regulates BRCA1 expression to modulate human breast tumor phenotype. J Clin Invest 120: 1535-1550

Guicciardi ME, Gores GJ (2009) Life and death by death receptors. FASEB J 23: $1625-1637$

Hoebeeck J, Michels E, Pattyn F, Combaret V, Vermeulen J, Yigit N, Hoyoux C, Laureys G, De Paepe A, Speleman F, Vandesompele J (2009) 
Aberrant methylation of candidate tumor suppressor genes in neuroblastoma. Cancer Lett 273: 336-346

Honorio S, Agathanggelou A, Wernert N, Rothe M, Maher ER, Latif $\mathrm{F}$ (2003) Frequent epigenetic inactivation of the RASSF1A tumour suppressor gene in testicular tumours and distinct methylation profiles of seminoma and nonseminoma testicular germ cell tumours. Oncogene 22: $461-466$

Hornstein M, Hoffmann MJ, Alexa A, Yamanaka M, Müller M, Jung V, Rahnenführer J, Schulz WA (2008) Protein phosphatase and TRAIL receptor genes as new candidate tumor genes on chromosome $8 \mathrm{p}$ in prostate cancer. Cancer Genomics Proteomics 5: $123-136$

Howard G, Eiges R, Gaudet F, Jaenisch R, Eden A (2008) Activation and transposition of endogenous retroviral elements in hypomethylation induced tumors in mice. Oncogene 27: 404-408

Ihara A, Wada K, Yoneda M, Fujisawa N, Takahashi H, Nakajima A (2007) Blockade of leukotriene B4 signaling pathway induces apoptosis and suppresses cell proliferation in colon cancer. J Pharmacol Sci 103: 24-32

Kaneuchi M, Sasaki M, Tanaka Y, Shiina H, Yamada H, Yamamoto R, Sakuragi N, Enokida H, Verma M, Dahiya R (2005) WT1 and WT1-AS genes are inactivated by promoter methylation in ovarian clear cell adenocarcinoma. Cancer 104: $1924-1930$

Karanikolas BD, Figueiredo ML, Wu L (2010) Comprehensive evaluation of the role of EZH2 in the growth, invasion, and aggression of a panel of prostate cancer cell lines. Prostate 70: 675-688

Kim PK, Mahidhara R, Seol DW (2001) The role of caspase- 8 in resistance to cancer chemotherapy. Drug Resist Updat 4: 293-296

Kotani $T$, Iwase A, Ino K, Sumigama S, Yamamoto E, Hayakawa H, Nagasaka T, Itakura A, Nomura S, Kikkawa F (2009) Activator protein-2 impairs the invasion of a human extravillous trophoblast cell line. Endocrinology 150: 4376-4385

Koul S, Houldsworth J, Mansukhani MM, Donadio A, McKiernan JM, Reuter VE, Bosl GJ, Chaganti RS, Murty VV (2002) Characteristic promoter hypermethylation signatures in male germ cell tumors. $\mathrm{Mol}$ Cancer 1: 8

Koul S, McKiernan JM, Narayan G, Houldsworth J, Bacik J, Dobrzynski DL, Assaad AM, Mansukhani M, Reuter VE, Bosl GJ, Chaganti RS, Murty VV (2004) Role of promoter hypermethylation in cisplatin treatment response of male germ cell tumors. Mol Cancer 3: 16

Krop I, Parker MT, Bloushtain-Qimron N, Porter D, Gelman R, Sasaki H, Maurer M, Terry MB, Parsons R, Polyak K (2005) HIN-1, an inhibitor of cell growth, invasion, and AKT activation. Cancer Res 65: 9659-9669

Li H, Goswami PC, Domann FE (2006) AP-2gamma induces p21 expression, arrests cell cycle, and inhibits the tumor growth of human carcinoma cells. Neoplasia 8: $568-577$

Liang G, Robertson KD, Talmadge C, Sumegi J, Jones PA (2000) The gene for a novel transmembrane protein containing epidermal growth factor and follistatin domains is frequently hypermethylated in human tumor cells. Cancer Res 60: 4907-4912

Lind GE, Skotheim RI, Fraga MF, Abeler VM, Esteller M, Lothe RA (2006) Novel epigenetically deregulated genes in testicular cancer include homeobox genes and SCGB3A1 (HIN-1). J Pathol 210: 441-449

Lind GE, Skotheim RI, Lothe RA (2007) The epigenome of testicular germ cell tumors. APMIS 115: 1147-1160

Looijenga LH (2009) Human testicular (non)seminomatous germ cell tumours: the clinical implications of recent pathobiological insights. J Pathol 218: $146-162$

Lung HL, Cheung AK, Cheng Y, Kwong FM, Lo PH, Law EW, Chua D, Zabarovsky ER, Wang N, Tsao SW, Stanbridge EJ, Lung ML (2010) Functional characterization of THY 1 as a tumor suppressor gene with antiinvasive activity in nasopharyngeal carcinoma. Int J Cancer 127: $304-312$

Manton KJ, Douglas ML, Netzel-Arnett S, Fitzpatrick DR, Nicol DL, Boyd AW, Clements JA, Antalis TM (2005) Hypermethylation of the $5^{\prime}$ $\mathrm{CpG}$ island of the gene encoding the serine protease Testisin promotes its loss in testicular tumorigenesis. Br J Cancer 92: 760-769

Martin-Perez D, Sanchez E, Maestre L, Suela J, Vargiu P, Di Lisio L, Martinez N, Alves J, Piris MA, Sanchez-Beato M (2010) Deregulated expression of the polycomb-group protein SUZ12 target genes characterizes mantle cell lymphoma. Am J Pathol 177: 930-942

Martin-Subero JI, Ammerpohl O, Bibikova M, Wickham-Garcia E, Agirre X, Alvarez S, Bruggemann M, Bug S, Calasanz MJ, Deckert M, Dreyling M, Du MQ, Durig J, Dyer MJ, Fan JB, Gesk S, Hansmann ML, Harder L, Hartmann S, Klapper W, Kuppers R, Montesinos-Rongen M, Nagel I, Pott C, Richter J, Roman-Gomez J, Seifert M, Stein H, Suela J, Trumper L, Vater I, Prosper F, Haferlach C, Cruz Cigudosa J, Siebert R (2009) A comprehensive microarray-based DNA methylation study of 367 hematological neoplasms. PLoS One 4: e6986

Masumoto J, Dowds TA, Schaner P, Chen FF, Ogura Y, Li M, Zhu L, Katsuyama T, Sagara J, Taniguchi S, Gumucio DL, Nunez G, Inohara N (2003) ASC is an activating adaptor for NF-kappa B and caspase-8dependent apoptosis. Biochem Biophys Res Commun 303: 69-73

Masumoto J, Taniguchi S, Ayukawa K, Sarvotham H, Kishino T, Niikawa N, Hidaka E, Katsuyama T, Higuchi T, Sagara J (1999) ASC, a novel 22-kDa protein, aggregates during apoptosis of human promyelocytic leukemia HL-60 cells. J Biol Chem 274: 33835-33838

McConnell BB, Vertino PM (2004) TMS1/ASC: the cancer connection. Apoptosis 9: 5-18

Mhyre AJ, Marcondes AM, Spaulding EY, Deeg HJ (2009) Stromadependent apoptosis in clonal hematopoietic precursors correlates with expression of PYCARD. Blood 113: 649-658

Mostert M, Rosenberg C, Stoop H, Schuyer M, Timmer A, Oosterhuis W, Looijenga L (2000) Comparative genomic and in situ hybridization of germ cell tumors of the infantile testis. Lab Invest 80: 1055-1064

Motani K, Kawase K, Imamura R, Kinoshita T, Kushiyama H, Suda T (2010) Activation of ASC induces apoptosis or necrosis, depending on the cell type, and causes tumor eradication. Cancer Sci 101: 1822-1827

Motiwala T, Kutay H, Ghoshal K, Bai S, Seimiya H, Tsuruo T, Suster S, Morrison C, Jacob ST (2004) Protein tyrosine phosphatase receptor-type O (PTPRO) exhibits characteristics of a candidate tumor suppressor in human lung cancer. Proc Natl Acad Sci USA 101: 13844-13849

Murray MJ, Saini HK, van Dongen S, Palmer RD, Muralidhar B, Pett MR, Piipari M, Thornton CM, Nicholson JC, Enright AJ, Coleman N (2010) The two most common histological subtypes of malignant germ cell tumour are distinguished by global microRNA profiles, associated with differential transcription factor expression. Mol Cancer 9: 290

Noushmehr H, Weisenberger DJ, Diefes K, Phillips HS, Pujara K, Berman BP, Pan F, Pelloski CE, Sulman EP, Bhat KP, Verhaak RG Hoadley KA, Hayes DN, Perou CM, Schmidt HK, Ding L, Wilson RK, Van Den Berg D, Shen H, Bengtsson H, Neuvial P, Cope LM, Buckley J, Herman JG, Baylin SB, Laird PW, Aldape K (2010) Identification of a CpG island methylator phenotype that defines a distinct subgroup of glioma. Cancer Cell 17: 510-522

Oosterhuis JW, Looijenga LH (2005) Testicular germ-cell tumours in a broader perspective. Nat Rev Cancer 5: 210-222

Palmer RD, Barbosa-Morais NL, Gooding EL, Muralidhar B, Thornton CM, Pett MR, Roberts I, Schneider DT, Thorne N, Tavare S, Nicholson JC, Coleman N (2008) Pediatric malignant germ cell tumors show characteristic transcriptome profiles. Cancer Res 68: 4239-4247

Qian ZR, Sano T, Yoshimoto K, Asa SL, Yamada S, Mizusawa N, Kudo E (2007) Tumor-specific downregulation and methylation of the $\mathrm{CDH} 13$ (H-cadherin) and $\mathrm{CDH} 1$ (E-cadherin) genes correlate with aggressiveness of human pituitary adenomas. Mod Pathol 20: 1269-1277

Rathi A, Virmani AK, Harada K, Timmons CF, Miyajima K, Hay RJ, Mastrangelo D, Maitra A, Tomlinson GE, Gazdar AF (2003) Aberrant methylation of the HICl promoter is a frequent event in specific pediatric neoplasms. Clin Cancer Res 9: 3674-3678

Richter J, Ammerpohl O, Martin-Subero JI, Montesinos-Rongen M, Bibikova M, Wickham-Garcia E, Wiestler OD, Deckert M, Siebert R (2009) Array-based DNA methylation profiling of primary lymphomas of the central nervous system. BMC Cancer 9: 455

Rickert CH (1999) Neuropathology and prognosis of foetal brain tumours. Acta Neuropathol (Berl) 98: 567-576

Rodrigues S, De Wever O, Bruyneel E, Rooney RJ, Gespach C (2007) Opposing roles of netrin-1 and the dependence receptor DCC in cancer cell invasion, tumor growth and metastasis. Oncogene 26: 5615-5625

Schulz WA, Steinhoff C, Florl AR (2006) Methylation of endogenous human retroelements in health and disease. Curr Top Microbiol Immunol 310: $211-250$

Sengupta PK, Smith EM, Kim K, Murnane MJ, Smith BD (2003) DNA hypermethylation near the transcription start site of collagen alpha2(I) gene occurs in both cancer cell lines and primary colorectal cancers. Cancer Res 63: 1789-1797

Shaffer JM, Smithgall TE (2009) Promoter methylation blocks FES proteintyrosine kinase gene expression in colorectal cancer. Genes Chromosomes Cancer 48: $272-284$

Shen L, Toyota M, Kondo Y, Lin E, Zhang L, Guo Y, Hernandez NS, Chen X, Ahmed S, Konishi K, Hamilton SR, Issa JP (2007) Integrated genetic and epigenetic analysis identifies three different subclasses of colon cancer. Proc Natl Acad Sci USA 104: 18654-18659 
Shi Y, He B, Kuchenbecker KM, You L, Xu Z, Mikami I, Yagui-Beltran A, Clement G, Lin YC, Okamoto J, Bravo DT, Jablons DM (2007) Inhibition of Wnt-2 and galectin-3 synergistically destabilizes beta-catenin and induces apoptosis in human colorectal cancer cells. Int J Cancer 121: $1175-1181$

Skakkebaek NE, Berthelsen JG, Giwercman A, Muller J (1987) Carcinoma-in-situ of the testis: possible origin from gonocytes and precursor of all types of germ cell tumours except spermatocytoma. Int J Androl 10: 19-28

Smith-Sorensen B, Lind GE, Skotheim RI, Fossa SD, Fodstad O, Stenwig AE, Jakobsen KS, Lothe RA (2002) Frequent promoter hypermethylation of the O6-methylguanine-DNA methyltransferase (MGMT) gene in testicular cancer. Oncogene 21: 8878-8884

Suzuki R, Shimodaira H (2006) Pvclust: an R package for assessing the uncertainty in hierarchical clustering. Bioinformatics 22: 1540-1542

Tabata T, Tsukamoto N, Fooladi AA, Yamanaka S, Furukawa T, Ishida M, Sato D, Gu Z, Nagase H, Egawa S, Sunamura M, Horii A (2009) RNA interference targeting against S100A4 suppresses cell growth and motility and induces apoptosis in human pancreatic cancer cells. Biochem Biophys Res Commun 390: 475-480

Tatsumi N, Oji Y, Tsuji N, Tsuda A, Higashio M, Aoyagi S, Fukuda I, Ito K, Nakamura J, Takashima S, Kitamura Y, Miyai S, Jomgeow T, Li Z, Shirakata T, Nishida S, Tsuboi A, Oka Y, Sugiyama H (2008) Wilms' tumor gene WT1-shRNA as a potent apoptosis-inducing agent for solid tumors. Int J Oncol 32: 701-711

Tomita T, Yamada A, Miyakoshi M, Kido T, Sheikh F, Srisodsai A, Miyajima A, Donnelly RP, Kimura S (2009) Oncostatin M regulates secretoglobin $3 \mathrm{~A} 1$ and $3 \mathrm{~A} 2$ expression in a bidirectional manner. $\mathrm{Am} \mathrm{J}$ Respir Cell Mol Biol 40: 620-630

Tomlins SA, Mehra R, Rhodes DR, Cao X, Wang L, Dhanasekaran SM, Kalyana-Sundaram S, Wei JT, Rubin MA, Pienta KJ, Shah RB, Chinnaiyan AM (2007) Integrative molecular concept modeling of prostate cancer progression. Nat Genet 39: 41-51

Toyota M, Ahuja N, Ohe-Toyota M, Herman JG, Baylin SB, Issa JP (1999) CpG island methylator phenotype in colorectal cancer. Proc Natl Acad Sci USA 96: 8681 - 8686

Tseng RC, Lee SH, Hsu HS, Chen BH, Tsai WC, Tzao C, Wang YC (2010) SLIT2 attenuation during lung cancer progression deregulates betacatenin and E-cadherin and associates with poor prognosis. Cancer Res 70: $543-551$

Veltman IM, Schepens MT, Looijenga LH, Strong LC, van Kessel AG (2003) Germ cell tumours in neonates and infants: a distinct subgroup? APMIS 111: $152-160$
Voisset E, Lopez S, Chaix A, Vita M, George C, Dubreuil P, De Sepulveda P (2010) FES kinase participates in KIT-ligand induced chemotaxis. Biochem Biophys Res Commun 393: 174-178

Wang J, Walsh G, Liu DD, Lee JJ, Mao L (2006) Expression of Delta DNMT3B variants and its association with promoter methylation of p16 and RASSF1A in primary non-small cell lung cancer. Cancer Res 66: $8361-8366$

Wang T, Liu H, Chen Y, Liu W, Yu J, Wu G (2009) Methylation associated inactivation of RASSF1A and its synergistic effect with activated K-Ras in nasopharyngeal carcinoma. J Exp Clin Cancer Res 28: 160

Weber B, Kimhi S, Howard G, Eden A, Lyko F (2010) Demethylation of a LINE-1 antisense promoter in the cMet locus impairs Met signalling through induction of illegitimate transcription. Oncogene 29: $5775-5784$

Weisenberger DJ, Siegmund KD, Campan M, Young J, Long TI, Faasse MA, Kang GH, Widschwendter M, Weener D, Buchanan D, Koh H, Simms L, Barker M, Leggett B, Levine J, Kim M, French AJ, Thibodeau SN, Jass J, Haile R, Laird PW (2006) CpG island methylator phenotype underlies sporadic microsatellite instability and is tightly associated with BRAF mutation in colorectal cancer. Nat Genet 38: $787-793$

Wong JM, Chi SN, Marcus KJ, Levine BS, Ullrich NJ, MacDonald S, Lechpammer M, Goumnerova LC (2010) Germinoma with malignant transformation to nongerminomatous germ cell tumor. J Neurosurg 6: $295-298$

Yamashita M, Toyota M, Suzuki H, Nojima M, Yamamoto E, Kamimae S, Watanabe Y, Kai M, Akashi H, Maruyama R, Sasaki Y, Yamano H, Sugai T, Shinomura Y, Imai K, Tokino T, Itoh F (2010) DNA methylation of interferon regulatory factors in gastric cancer and noncancerous gastric mucosae. Int J Cancer 101: 1708-1716

Yang A, EsteÂcio M, Doshi K, Kondo Y, Tajara E, Issa J-P (2004) A simple method for estimating global DNA methylation using bisulfite PCR of repetitive DNA elements. Nucleic Acids Res 32: e38

Yiin JJ, Hu B, Jarzynka MJ, Feng H, Liu KW, Wu JY, Ma HI, Cheng SY (2009) Slit2 inhibits glioma cell invasion in the brain by suppression of Cdc42 activity. Neuro Oncol 11: 779-789

Zhai Y, Bommer GT, Feng Y, Wiese AB, Fearon ER, Cho KR (2010) Loss of estrogen receptor 1 enhances cervical cancer invasion. Am J Pathol 177: $884-895$

Zhang Y, Song H, Miao Y, Wang R, Chen L (2010) Frequent transcriptional inactivation of kallikrein 10 gene by $\mathrm{CpG}$ island hypermethylation in non-small cell lung cancer. Cancer Sci 101: 934-940 